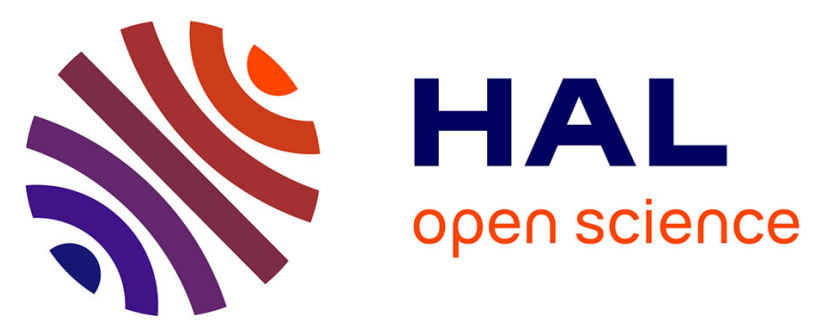

\title{
Stimulus duration thresholds for reading numerical time information: Effects of visual size and number of time units
}

Olivier Borg, Remy Casanova, Camille Coton, Charlie Barla, Reinoud J. Bootsma

\section{To cite this version:}

Olivier Borg, Remy Casanova, Camille Coton, Charlie Barla, Reinoud J. Bootsma. Stimulus duration thresholds for reading numerical time information: Effects of visual size and number of time units. Displays, 2015, 36, pp.30 - 33. 10.1016/j.displa.2014.11.003 . hal-01441653

\section{HAL Id: hal-01441653 https://hal-amu.archives-ouvertes.fr/hal-01441653}

Submitted on 9 May 2018

HAL is a multi-disciplinary open access archive for the deposit and dissemination of scientific research documents, whether they are published or not. The documents may come from teaching and research institutions in France or abroad, or from public or private research centers.
L'archive ouverte pluridisciplinaire HAL, est destinée au dépôt et à la diffusion de documents scientifiques de niveau recherche, publiés ou non, émanant des établissements d'enseignement et de recherche français ou étrangers, des laboratoires publics ou privés. 


\title{
Stimulus duration thresholds for reading numerical time information: Effects of visual size and number of time units
}

\author{
Olivier Borg ${ }^{1,2}$, Remy Casanova ${ }^{1}$, Camille Coton $^{2}$, \\ Charlie Barla ${ }^{2}$, and Reinoud J. Bootsma ${ }^{1}$ \\ ${ }^{1}$ Aix Marseille Université, CNRS, ISM UMR 7287, Marseille, France \\ ${ }^{2}$ Oxylane Research, Lille, France
}

Corresponding author:

Reinoud J. Bootsma

Institut des Sciences du Mouvement, UMR CNRS 7287

Aix-Marseille Université

163 avenue de Luminy

13009 Marseille

France

e-mail: reinoud.bootsma@univ-amu.fr

tel: +33491170455 


\begin{abstract}
We examined the effects of the visual size and the number of digits on reading numerical time information in young adults. Using an adaptive staircase procedure, minimal stimulus presentation duration (MSPD) for 80\%-correct responses was determined for visual sizes ranging from $0.1^{\circ}$ to $15^{\circ}$, when reading 1 (“"mm"), 2 ("hh:mm") or 3 ("hh:mm:ss") 2-digit units of time information. All three time types revealed U-shaped relations between MSPD and visual size, with the characteristics of the relation depending on the number of time units. Time type had two different effects. First, longer time types gave rise to longer MSPDs, as more elements needed to be encoded into working memory. Second, longer time types gave rise to smaller ranges of optimal visual character size, decreasing from $0.2^{\circ}-2^{\circ}$ for the 1 -unit time type to $0.3^{\circ}-0.5^{\circ}$ for the 3 -unit time type. The lower boundary of the optimal range of visual size may be understood as resulting from acuity limitations. The shift in the upper boundary of the optimal range of visual size is suggested to reflect the change in size of the visual span associated with larger visual character sizes.
\end{abstract}

Key-words: Number reading; visual size; perceptual threshold 


\section{Introduction}

A consequence of the increasing presence in daily life of electronic accessories with visual displays is that we are more and more confronted with numerical information. While numbers may of course be represented in word form by verbal numerals (e.g., "seven" or “twenty-four"), representation in digit form by Arabic numerals (e.g., "7” or "24”) allows a much more efficient use of presentation space. Numerical time information, for instance, is typically presented by two-digit groups of Arabic numerals, separated by colons.

Although digit-form numerical information is extensively used in displays, number legibility has not received the same amount of experimental attention as text legibility. As a result, visual ergonomics has either implicitly assimilated numbers to letters (or words) or has simply ignored them. Interestingly in this regard, the European standard of requirements for electronic visual displays (ISO 9241-303, 2011) defines minimal, maximal, and preferable visual sizes for text characters, but not for number characters. Yet, important neuroanatomical and functional differences have been demonstrated between number reading and text reading (Brysbaert, 1995; Butterworth, Cappelletti, \& Kopelman, 2001; Dehaene, 1992; Gallistel \& Gelman, 1992, 2000; McCloskey, 1992; Pesenti et al., 2000; Roux et al., 2008; Santens et al., 2009; Verguts \& Fias, 2004).

Low-level visual processes underlying the identification of individual digits may be expected to be similar to those underlying the identification of individual letters, but multidigit numbers cannot be assimilated with multi-letter words: The latter are characterized by recognizable global patterns that allow individual characters to be ignored (cf., Cattell, 1886; Reicher, 1969; Smith, 1969; Tinker, 1965; Woodworth, 1938) while the former are not. Moreover, while numbers can be formed by any combination of digits, certain combinations of letters form words while others do not. Using an established psychophysical method, in the 
present contribution we examined the effects of the visual size and the number of digits on reading numerically represented time information.

Under normal contrast and luminance conditions, the speed of text reading is maximal when the letter characters subtend visual angles between $0.3^{\circ}$ and $2^{\circ}$ (Chung et al., 1998; Legge et al., 1985). Below $0.3^{\circ}$ of visual angle text reading speed decreases (also see Lee, et al., 2011; Lin et al., 2013 for electronic devices), most likely due to limitations in visual acuity. Beyond $2^{\circ}$ of visual angle text reading speed also decreases, indicating that the use of larger characters is not necessarily beneficial (Legge et al., 1985; also see Wu \& Chan, 2006). This latter effect has been attributed to decreasing letter acuity in peripheral vision, crowding between adjacent characters, and decreasing accuracy of position signals in peripheral vision (Legge et al., 2007). These mechanisms can give rise to an increase in the number of fixations, separated by the saccadic eye movements that characterize text reading (Rubin \& Turano, 1992; Tinker, 1965). Because the effect of character size in text reading is thus mainly explained by low-level visual processing characteristics, one may expect similar effects of character size in number reading. Our working hypothesis was thus that number reading would reveal an optimal size interval that lies in the same range $\left(0.3-2^{\circ}\right.$ of visual angle) as that identified for text reading.

Word length is known to influence reading speed (Legge et al., 1997a), with longer words evoking longer fixation durations (Hautala et al., 2011; McDonald, 2006), presumably due to the increase in the quantity and complexity of information that needs to be processed (Rayner \& Duffy, 1986). Longer numbers (i.e., numbers with more digits) also require a longer processing time (Gallistel \& Gelman, 1992; Parkman, 1971), which is known as the magnitude effect (Brysbaert, 1995). Yet, processing of Arabic numbers is quite different from processing verbal material (Brysbaert, 1995; McClosky \& Macaruso, 1995; Roux et al., 2008; Santens et al., 2009) and therefore the reasons underlying the word-length effect cannot be 
directly transposed to the magnitude effect. Moreover, rather than giving rise to longer numbers, increasing the precision of numerical time information typically leads to seriesextensions of two-digit numbers, representing for instance hours (hh), minutes (mm), and seconds (ss). While it remains unclear whether two-digit numbers are processed separately or as an ensemble (Brysbaert, 1995; McCloskey, 1992; Moeller et al., 2009; Ratinckx et al., 2005), reading numerical time involves processing of a series of two-digit numbers. Based on the effects of the number of units to be processed on processing duration (e.g., Sternberg, 1966), an increase in the number of two-digit numbers is expected to lead to an increase in the required reading time.

In the present study we determined the minimal visual presentation duration required to accurately read numerical time information. Using a psychophysical staircasing procedure (Leek, 2001), we explored the effects of character size and number of two-digit information units.

\section{Material and Methods}

\subsection{Participants}

Twelve young adults ( 6 men and 6 women, age $21 \pm 5$ years) participated in the study. All had a corrected or uncorrected visual acuity of at least 10/10 for each eye, as determined by a 5-m Monoyer test. Participants provided written consent prior to the study, which was conducted according to University regulations and the Declaration of Helsinki.

\subsection{Apparatus and Stimuli}

Stimuli were presented in the center of a 22-inch LCD screen (Samsung SyncMaster 2233 RZ, 1680 x 1050 pixel resolution, 32-bit color coding) operating at $100 \mathrm{~Hz}$. Synchronization with the 10 -ms refreshment cycle of the screen was controlled by E-Prime ${ }^{\circledR} 2.0$ software (Psychology Software Tools, Inc., USA), running on a HP Z400 Workstation (Intel® Xeon ${ }^{\circledR}$ 
CPUW3520@2.67GHz 1.57GHz, 3 Go RAM, NVIDIA Quadro FX 1800 graphic card, Microsoft Windows XP Professional SP3 OS). Viewing distance was controlled using a frontal headrest that also ensured alignment of the participant's eyes with the center of the screen.

Stimuli consisted of combinations of one, two, or three two-digit groups, representing time information in a numerical format ("mm", "hh:mm" or "hh:mm:ss" with $00 \leq h \mathrm{~h}<24$; $00 \leq \mathrm{mm}<60 ; 00 \leq \mathrm{ss}<60$ ). Each stimulus presentation was immediately followed by a 500 -ms mask of the appropriate dimension (“\$\$, “\$\$:\$\$, “\$\$:\$\$:\$”). Characters were presented in the Digiface font (see Fig. 1), a constant-width font comparable to the 7-segment fonts used in classical LCD displays. They were presented in mesopic viewing conditions, in black against a white $110 \mathrm{~cd} / \mathrm{m}^{2}$-luminance background with a mean Michelson contrast of $85 \%$.

\section{***** Figure 1 about here $* * * * *$}

\subsection{Task and Procedure}

The duration of stimulus presentation varied sequentially over trials following an adaptive staircase procedure. On each trial, a fixation cross was presented in the center of the screen during $2 \mathrm{~s}$, followed by a stimulus (presented for a duration depending on the staircase procedure) and the 500-ms mask. Before the start of the experimental phase, participants were familiarized with the visual task during a one-minute training session with fixed and sufficiently long presentation durations.

During the experimental phase, after each stimulus presentation participants had to enter the perceived sequence of numbers on a keyboard placed on the table in front of them before the next trial started. Stimulus presentation duration was adapted during the sequence using an adaptive three-down/one-up staircase, leading to the threshold for $80 \%$ correct responses 
(Leek, 2001). Starting from a sufficiently long initial stimulus duration, this duration was decreased in time steps of $40 \mathrm{~ms}$ following each series of three consecutive correct responses. When an error occurred, duration was increased by $40 \mathrm{~ms}$. After the first four inversions, the time step was reduced to $20 \mathrm{~ms}$. After the next three inversions, the time step was further reduced to $10 \mathrm{~ms}$. The procedure ended after 12 inversions. The perceptual threshold (corresponding to the presentation duration for $80 \%$ correct responses) was calculated as the mean of the last four inversion values.

Perceptual thresholds were obtained for each of the three time types (formats "mm", "hh:mm", and "hh:mm:ss", corresponding to one, two, or three two-digit groups) at each of nine different sizes $\left(0.1^{\circ}, 0.2^{\circ}, 0.3^{\circ}, 0.5^{\circ}, 1.0^{\circ}, 2.0^{\circ}, 5.0^{\circ}, 10.0^{\circ}\right.$, and $15.0^{\circ}$ visual angle $)$.

To this end, participants performed a total of 9 blocks of trials - three for each time type with each block presenting three interlaced staircase procedures for the same time type $\left(\left[0.1^{\circ}\right.\right.$, $\left.0.2^{\circ}, 0.3^{\circ}\right]$ or $\left[0.5^{\circ}, 1.0^{\circ}, 2.0^{\circ}\right]$ or $\left.\left[5.0^{\circ}, 10.0^{\circ}, 15.0^{\circ}\right]\right)$. Blocks were presented in randomized order and lasted about 12 minutes per block. Participants rested for a minimum of 15 minutes between blocks.

The size and resolution of the screen used in the present experiment did not allow to correctly present stimulus for each visual size at a single viewing distance. Nevertheless, all tests were performed in binocular close viewing: $15 \mathrm{~cm}$ for the $5.0^{\circ}-10.0^{\circ}-15.0^{\circ}$ blocks and $65 \mathrm{~cm}$ for the other blocks. Each participant completed the full experimental session on a single day in order to minimize within-participant variability.

\subsection{Statistical analysis}

After verification of the normality of the data distribution with Lilliefors and ShapiroWilk tests, effects of Time Type and Visual Size on the perceptual thresholds were assessed using a two-way repeated-measures Analysis of Variance (ANOVA). Effect sizes were 
determined using partial $\eta^{2}$. Differences between conditions were further explored using Tukey HSD post-hoc tests.

\section{Results}

The ANOVA revealed significant main effects of both Time Type $(F(2,22)=338.6, p<$ $\left..001, \eta_{\mathrm{p}}^{2}=.97\right)$ and Visual Size $\left(F(8,88)=122.3, p<.001, \eta_{\mathrm{p}}^{2}=.92\right)$, as well as a significant Time Type $x$ Visual Size interaction $\left(F(16,176)=30,9, p<.001, \eta^{2}{ }_{\mathrm{p}}=.74\right)$. All effect sizes were large (cf. Cohen, 1977)

Post-hoc analysis of the overarching interaction revealed that Time Type significantly affected the perceptual thresholds at all levels of Visual Size. As can be seen from Figure 2, perceptual thresholds increased exponentially when the Time Type number of two-digit time units increased from 1 to 2 to 3 .

The post-hoc analysis also revealed that Visual Size affected the perceptual threshold for all levels of Time Type. For all three Time Types, perceptual thresholds varied as a function of Visual Size according to a U-shape, which became steeper for larger numbers of two-digit groups.

\footnotetext{
$* * * * *$ Figure 2 about here $* * * * *$
}

Finally, the post-hoc analysis revealed that Time Type influenced both the location and the extent of the minimum perceptual threshold as a function of Visual Size. For the threenumber Time Type, minimal perceptual thresholds (501 ms on the average) occurred at Visual Sizes of $0.3^{\circ}$ and $0.5^{\circ}$. While perceptual thresholds did not differ between these two sizes $(p=0.68)$, they were significantly lower than those of all other sizes (all $p \mathbf{s}<.05)$. For the two-number Time Type minimal perceptual thresholds (108 ms on the average) were found for Visual Sizes between $0.2^{\circ}$ and $1.0^{\circ}$ (all comparisons $p \mathrm{~s}>.05$ except $0.3^{\circ}$ vs. $1.0^{\circ}, p$ 
$=.045)$. The perceptual thresholds for this range of Visual Size were significantly lower than those of all other Visual Sizes (all $p$ s $<.05$ ). Finally, for the one-number Time Type, minimal perceptual thresholds ( $52 \mathrm{~ms}$ on the average) were found for Visual sizes between $0.2^{\circ}$ and $2.0^{\circ}$ (all comparisons $p \mathrm{~s}>.05$ except $1.0^{\circ}$ vs. $2.0^{\circ}, p=.038$ ). The perceptual thresholds for this range of Visual Size were significantly lower than those of all other Visual Sizes (all $p \mathrm{~s}<$ $.05)$.

\section{Discussion}

This study examined the effects of visual character size and time type (number of twodigit units of temporal information) on the minimal stimulus presentation duration (MSPD) required for reading numerical time information. The range of visual character sizes explored $\left(0.1^{\circ}-15^{\circ}\right)$ was inspired by previous work on reading textual information (Chung et al., 1998; Legge et al., 1985) and proved to be satisfactory for the present purposes.

Our results revealed the existence of U-shaped relationships between MSPD and visual size, with the characteristics of the relation depending on time type. Even for optimal visual sizes, the perceptual threshold as determined by MSPD increased from $52 \mathrm{~ms}$ for the onenumber time type (mm), via $108 \mathrm{~ms}$ for the two-number time type (hh:mm), to $501 \mathrm{~ms}$ for the three-number time type (hh:mm:ss). This heightening of the perceptual threshold with an increase in the number of time units was accompanied by a reduction in the range of visual sizes revealing optimal performance, decreasing from $\left[0.2^{\circ} ; 2.0^{\circ}\right]$ for the one-number time type, via $\left[0.2^{\circ} ; 1.0^{\circ}\right]$ for the two-number time type, to $\left[0.3^{\circ} ; 0.5^{\circ}\right]$ for the three-number time type.

The processes underlying the coding of information for storage in working memory explain the observed effect of the number of time units on MSPD. Pynte (1974) suggested that number reading is based on phonological encoding (see Baddeley, 1966; Baddeley et al., 1975; Conrad, 1964; Levy, 1971; Watkins \& Watkins, 1973), with syllables constituting the 
elementary units. For the task of typing out a series of silently-read numbers presented with a large visual separation, Gielen et al. (1991) demonstrated that first-fixation duration and firstgaze duration on a number were related to the number of syllables of the number name.

Whatever the precise mode of encoding used by our participants, the number of elements to be encoded clearly increased from the "mm" via the "hh:mm" to the "hh:mm:ss" time type, thereby leading to the lengthening of the MSPD.

The observed reduction in the range of optimal visual sizes with increasing numbers of time information units may have several different causes. The number of characters that can be recognized within a single fixation defines a visual span (Chung et al., 1998; Legge et al., 1997b, 2001, 2007; O'Regan, 1990, 1991; Yu et al., 2009). Several text-reading studies have suggested that the size of the visual span is more or less constant- - on the order of 10 characters - for visual character sizes between $0.3^{\circ}$ and $1.0^{\circ}$ (Legge et al., 1997a, 1997b; O’Regan et al., 1983; Rayner \& Bertera, 1979), but progressively decreases when visual character size increases beyond $1^{\circ}$. Although to our knowledge the size of the visual span has not been addressed in number-reading, we may assume that, as in text-reading, it decreases progressively for visual character sizes at the high end of the range examined in this study. Indeed, of the three sensory mechanisms (decreasing letter acuity in peripheral vision, crowding between adjacent characters, and decreasing accuracy of position signals in peripheral vision) underlying this effect (Legge et al., 2007), only crowding (Chung et al., 2001) might be expected to play less of a role in reading numerical time information due to the presence of separators. The visual span hypothesis (Legge et al., 1997a, 1997b, 2007) predicts the observed lowering of the upper boundary of the range of optimal visual sizes as the number of time units increases. The stronger increase in MSPD observed in the range of visual sizes between $2^{\circ}$ and $15^{\circ}$ for the longer time types also fits this hypothesis. When the quantity of temporal information presented exceeds the visual span, it can no longer be read 
within a single fixation. The additional fixations required (Rubin \& Turano, 1994) lead to a rapid increase in MSPD. The visual span hypothesis can thus explain the effects observed at the high end of the range of visual sizes studied.

Below $0.2^{\circ}$ of visual angle, MSPD rapidly increased, undoubtedly due to acuity limitations (Legge et al., 1985). The progressive loss of acuity that characterizes the visual field from the point of fixation outward (Legge et al., 1997a, 2007) provides an explanation for the stronger rise in MSPD observed for larger number of time units when visual sizes decrease below the optimal range: the larger the number of two-digit time units that needs to be read in a single fixation, the more they will occupy the lower-acuity periphery, thereby leading to a lengthening of the MSPD. For the three-number time type, this effect gives rise to a heightening (from $0.2^{\circ}$ to $0.3^{\circ}$ ) of the lower boundary of optimal visual size.

In conclusion, the psychophysics of reading numerical time information shows certain similarities with text reading, but also reveals differences that should be considered in designing interfaces presenting numerical time information. As in reading text, reading numerical time information is optimal when presented within a particular range of visual sizes, constrained on the lower end by the acuity of the visual system and on the upper end by the visual span, that is, the number of characters that can be processed within a single fixation. However, more so than in text reading, reading numerical information is strongly affected by the number of items to be read. Increasing the number of two-digit groups gives rise not only to a substantial lengthening of the time required for accurate reading, but also reduces the range of optimal visual sizes, from $0.2^{\circ}-2.0^{\circ}$ for a single two-digit number to $0.3^{\circ}-0.5^{\circ}$ for three two-digit numbers. 


\section{References}

Baddeley, A.D. (1966). Short-term memory for word sequences as a function of acoustic, semantic and formal similarity. Quarterly Journal of Experimental Psychology, 18, 362365.

Baddeley, A.D., Thomson, N., \& Buchanan, M. (1975). Word length and the structure of short-term memory. Journal of Verbal Learning and Verbal Behavior, 14, 575-589.

Brysbaert, M. (1995). Arabic number reading: On the nature of the numerical scale and the origin of phonological recoding. Journal of Experimental Psychology: General, 124, $434-452$.

Butterworth, B., Cappelletti, M., \& Kopelman, M. (2001). Category specificity in reading and writing: the case of number words. Nature Neuroscience, 4, 784-786.

Cattell, J. (1886). The time taken up by cerebral operations. Mind, 11, 220-242.

Chung, S. T. L., Levi, D. M., \& Legge, G. E. (2001). Spatial-frequency and contrast properties of crowding. Vision research, 41, 1833-1850.

Chung, S.T.L., Mansfield, J.S., \& Legge, G.E. (1998). Psychophysics of reading. XVIII. The effect of print size on reading speed in normal peripheral vision. Vision Research, 38, 29492962.

Cohen, J. (1977). Statistical Power Analysis for the Behavioural Sciences, revised ed. Academic Press, New York.

Conrad, R. (1964). Acoustic confusion in immediate memory. British Journal of Psychology, $55,75-84$.

Dehaene, S. (1992). Varieties of numerical abilities. Cognition, 44, 1-42.

Gallistel, C.R., \& Gelman, R. (1992). Preverbal and verbal counting and computation. Cognition, 44, 43-74. 
Gallistel, C.R., \& Gelman, R. (2000). Non-verbal numerical cognition: From reals to integers. Trends in Cognitive Sciences, 4, 59-65.

Gielen, I., Brysbaert, M., \& Dhondt, A. (1991). The syllable-length effect in number processing is task-dependent. Perception \& Psychophysics, 50, 449-458.

Hautala, J., Hyönä, J., \& Aro, M. (2011). Dissociating spatial and letter-based word length effects observed in readers' eye movement patterns. Vision Research, 51, 1719-1727.

ISO 9241-303 (2011). Ergonomics of human-system interaction — Part 303: Requirements for electronic visual displays.

Lee, D.-S., Ko, Y.-H., Shen, I.-H., \& Chao, C.-Y. (2011). Effect of light source, ambient illumination, character size and interline spacing on visual performance and visual fatigue with electronic paper displays. Displays, 32(1), 1-7.

Leek, M.R. (2001). Adaptive procedures in psychophysical research. Perception \&Psychophysics, 63, 1279-1292

Legge, G. E., Cheung, S. H., Yu, D., Chung, S. T. L., Lee, H. W., \& Owens, D. P. (2007). The case for the visual span as a sensory bottleneck in reading. Journal of Vision, 7(2), 9-9. doi:10.1167/7.2.9.

Legge, G.E., Ahn, S.J., Klitz, T.S., \& Luebker, A. (1997a). Psychophysics of reading: XVI. The visual span in normal and low vision. Vision Research, 37, 1999-2010.

Legge, G.E., Klitz, T.S., \&Tjan, B.S. (1997b). Mr. Chips: An ideal-observer model of reading. Psychological Review, 104, 524-553.

Legge, G.E., Mansfield, J.S., \& Chung, S.T.L. (2001). Psychophysics of reading: XX. Linking letter recognition to reading speed in central and peripheral vision. Vision Research, 41, 725-743.

Legge, G.E., Pelli, D.G., Rubin, G.S., \& Schleske, M.M. (1985). Psychophysics of reading: I. Normal vision. Vision Research, 25, 239-252.

Levy, B., A. (1971). The role of articulation in auditory and visual short-term memory. 
Journal of Verbal Learning and Verbal Behavior, 10, 123-132.

Lin, H., Wu, F.-G., \& Cheng, Y.-Y. (2013). Legibility and visual fatigue affected by text direction, screen size and character size on color LCD e-reader. Displays, 34(1), 49-58.

McCloskey, M. (1992). Cognitive mechanisms in numerical processing: Evidence from acquired dyscalculia. Cognition, 44, 107-157.

McCloskey, M., \& Macaruso, P. (1995). Representing and using numerical information. American Psychologist, 50, 351-363.

McDonald, S.A. (2006). Effects of number-of-letters on eye movements during reading are independent from effects of spatial word length. Visual Cognition, 13, 89-98.

Moeller, K., Nuerk, H.-C., \& Willmes, K. (2009). Internal number magnitude representation is not holistic, either. European Journal of Cognitive Psychology, 21, 672-685.

O'Regan, J.K. (1990). Eye movements and reading. In: Kowler, E. (Ed.), Eye Movements and their Role in Visual and Cognitive Processes. Elsevier, New York, pp. 395-453.

O'Regan, J.K. (1991). Understanding visual search and reading using the concept of stimulus “grain”. IPO Annual Progress Reports, 26, 96-108.

O'Regan, J.K., Levy-Schoen, A., \& Jacobs, A.M. (1983). The effect of visibility on eyemovement parameters in reading. Perception and Psychophysics, 34, 457-464.

Parkman, J.M. (1971). Temporal aspects of digit and letter inequality judgments. Journal of Experimental Psychology, 91, 191-205.

Pesenti, M., Thioux, M., Seron, X., \& De Volder, A. (2000). Neuroanatomical substrates of arabic number processing, numerical comparison, and simple addition: a PET study. Journal of Cognitive Neuroscience, 12, 461-479.

Pynte, J. (1974). Readiness for pronunciation during the reading process. Perception \& Psychophysics, 16, 110-112. 
Ratinckx, E., Brysbaert, M.,\& Fias, W. (2005). Naming two-digit Arabic numerals: Evidence from masked priming studies. Journal of Experimental Psychology: Human Perception and Performance, 31, 1150-1163.

Rayner, K. (2009). Eye movements and attention in reading, scene perception, and visual search. The Quarterly Journal of Experimental Psychology, 62, 1457-1506.

Rayner, K., \& Bertera, J. H. (1979). Reading without a fovea. Science, 206, 468-469.

Rayner, K., \& Duffy, S.A. (1986). Lexical complexity and fixation times in reading: Effects of word frequency, verb complexity, and lexical ambiguity. Memory \& Cognition, 14, 191-201.

Reicher, G.M. (1969). Perceptual recognition as a function of meaningfulness of stimulus material. Journal of Experimental Psychology, 81, 275-280.

Roux, F.-E., Lubrano, V., Lauwers-Cances, V., Giussani, C., \& Démonet, J.-F. (2008). Cortical areas involved in Arabic number reading. Neurology, 70, 210-217.

Rubin, G.S., \& Turano, K. (1992). Reading without saccadic eye movements. Vision Research, 32, 895-902.

Rubin, G.S., \& Turano, K. (1994). Low vision reading with sequential word presentation. Vision Research, 34, 1723-1733.

Santens, S., Roggeman, C., Fias, W., \& Verguts, T. (2009). Number processing pathways in human parietal cortex. Cerebral Cortex, 20, 77-88.

Smith, F. (1969). Familiarity of configuration vs. discriminability of features in the visual identification of words. Psychonomic Science, 14, 261-262.

Sternberg, S. (1966). High-speed scanning in human memory. Science, 153, 652-654.

Tinker, M.A. (1965). Bases for Effective Reading. University of Minnesota Press, Minneapolis. 
Verguts, T., \& Fias, W. (2004). Representation of number in animals and humans: a neural model. Journal of Cognitive Neuroscience, 16, 1493-1504.

Watkins, M.J., \& Watkins, O.C. (1973). The postcategorical status of the modality effect in serial recall. Journal of Experimental Psychology, 99, 226-230.

Woodworth, R.S. (1938). Experimental Psychology. Holt, New York.

Wu, H.C., \& Chan, C. (2006). Determining suitable character size for reading from an ebook. Proceedings of the 6th WSEAS International Conference on Applied Informatics and Communications, Elounda, Greece, August 18-20, 2006 (pp 146-150).

Yu, D., Cheung, S.-H., Legge, G.E., \& Chung, S.T.L. (2009). Effect of letter spacing on visual span and reading speed. Journal of Vision, 7(2):2, 1-10. 


\section{Figure Captions}

Figure 1: Numerical characters of the Digiface font (A), examples of stimuli in the "mm" (B), "hh:mm" (C), and "hh:mm:ss" (D) time type formats.

Figure 2: Minimal Stimulus Presentation Duration (MSPD) as a function of visual size for each of the three Time Types (logarithmic scales). For each time type the range of sizes revealing minimal duration thresholds is indicated by black line segment(s). Error bars represent inter-individual standard deviations. 
Figure 1
$\begin{array}{llll}\text { (A) } 1 \text { (C) } 0937 & \text { (D) } 23: 45: 08\end{array}$

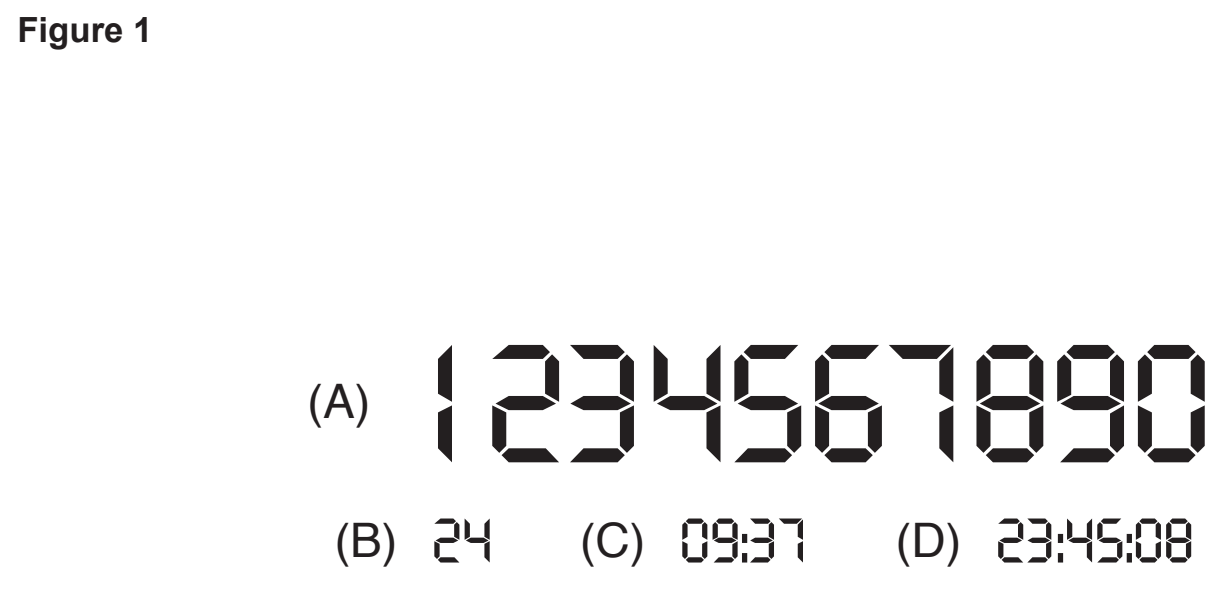

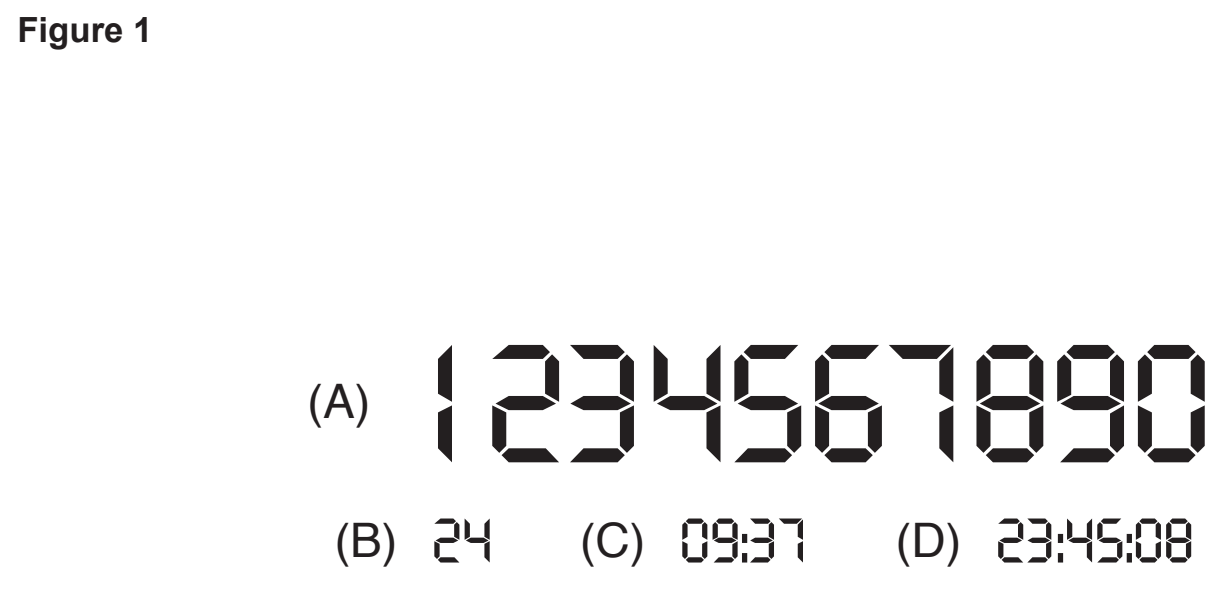

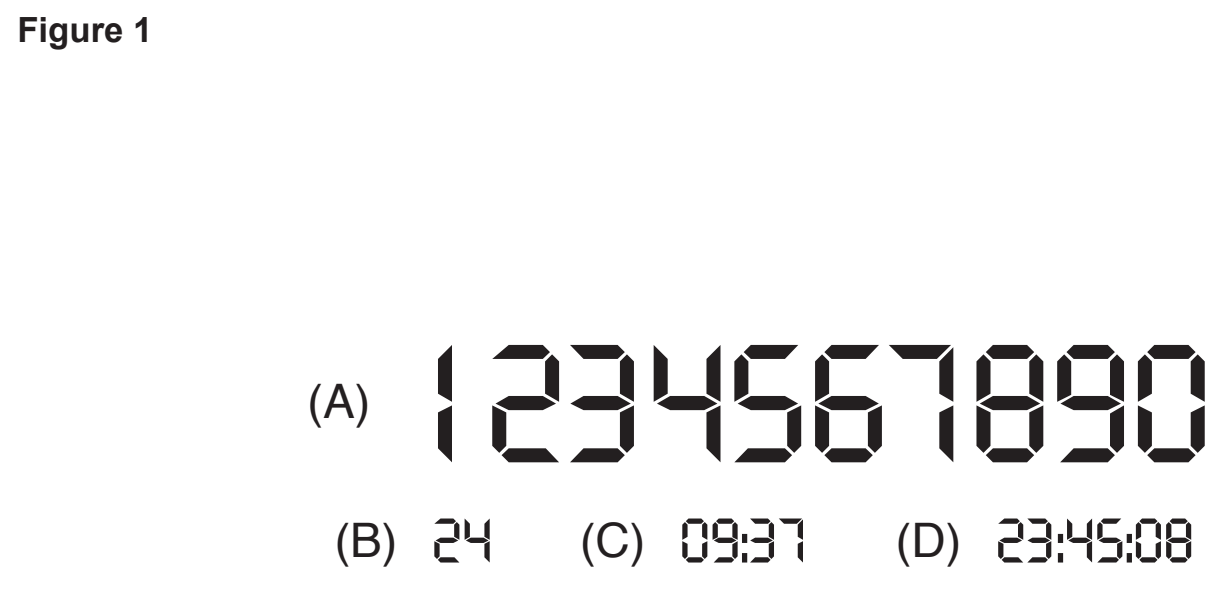

.

-

.

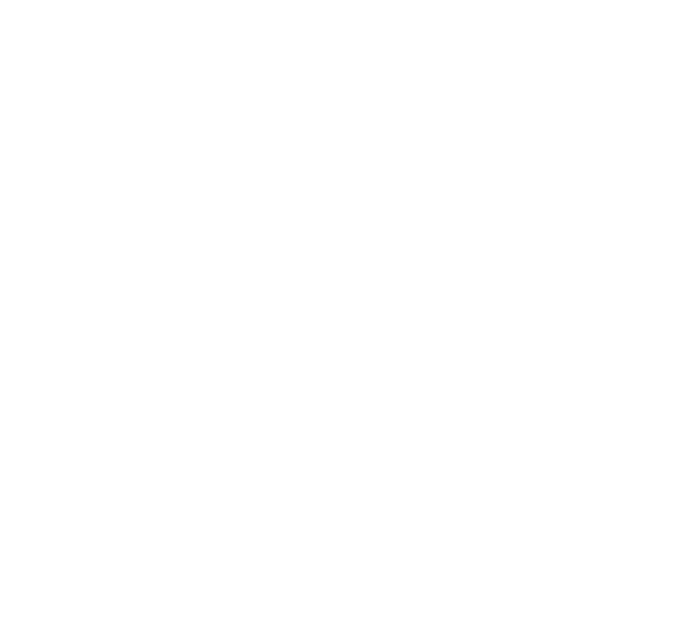

政

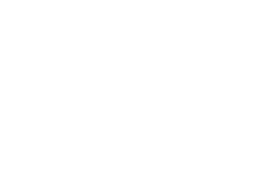
(2) -
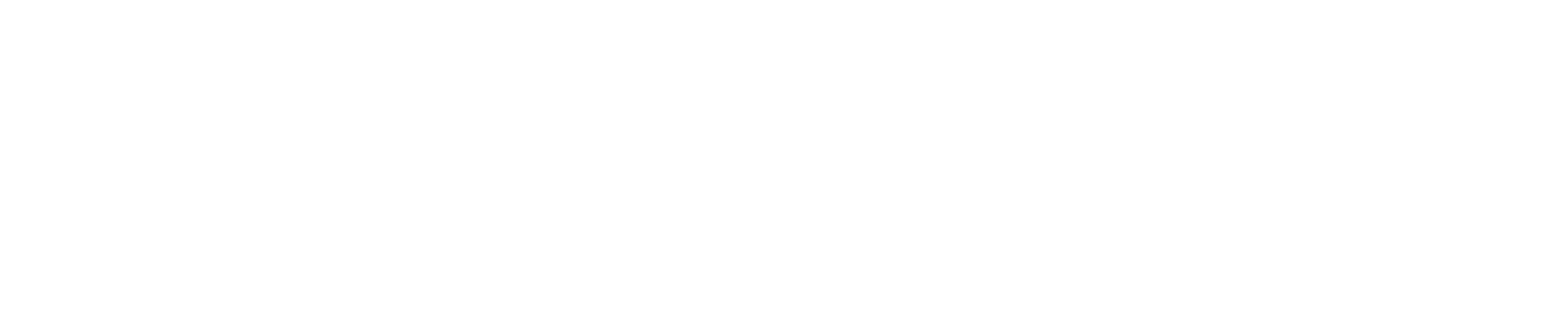

政 


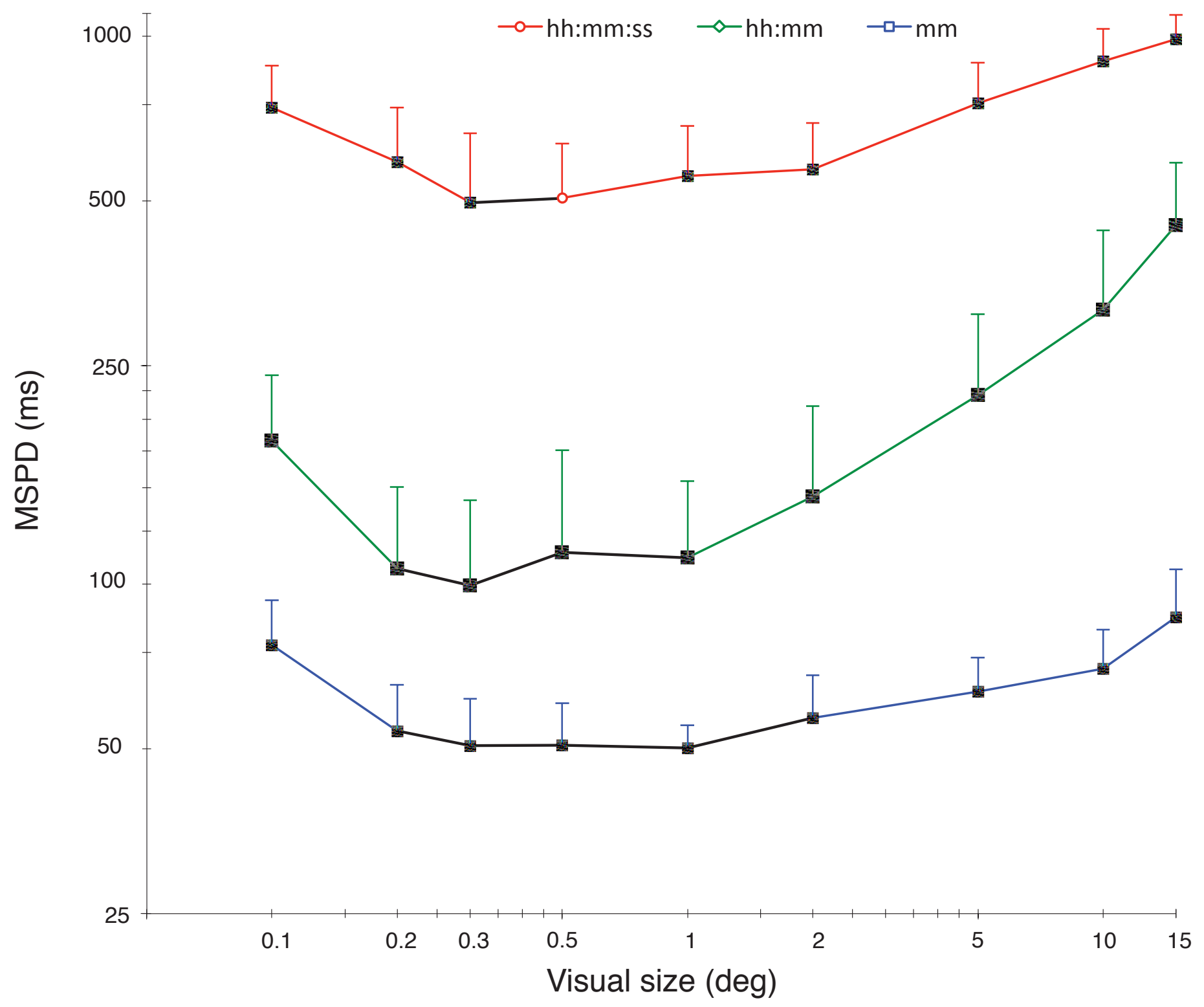

